\title{
A Review of the Research Progress of China's Long-term Care Insurance
}

\author{
Wu Jingting ${ }^{1, *}$, Zhang Wenjing ${ }^{2}$ \\ ${ }^{1}$ Institute of Political Science and Law, University of Jinan, Jinan, Shandong, China \\ ${ }^{2}$ Research Office, Women's Development Research Center of Shandong Province, Jinan, Shandong, China \\ *Corresponding author. Email: $1446496572 @ q q . c o m$
}

\begin{abstract}
As the aging of the population continues to deepen and the scale of disabled and semi-disabled elderly continues to expand, China urgently needs to establish a long-term care insurance system to solve the increasingly serious elderly care problems. Starting from the concept definition, development models, demand influencing factors, necessity and feasibility, pilot projects and other aspects of long-term care insurance, this paper sorted out the research history and latest progress of long-term care insurance in China, in order to integrate relevant background knowledge, clarify the development context, and find the problems to be solved.
\end{abstract}

Keywords: Long-term care insurance, Research progress, Review

\section{DEFINITION OF LONG-TERM CARE INSURANCE}

Long-term care insurance first appeared in America in the 1970s. After long-term development, it eventually forms three representative modes: mandatory long-term care social insurance system represented by Germany and Japan, voluntary long-term care commercial insurance system represented by the United States, and welfare long-term care system represented by the United Kingdom.

At present, Chinese academic circles have not yet formed a unified understanding of the concept of long-term care insurance. Chinese official documents define the long-term care (social) insurance as "a social insurance system that provides services or financial guarantees for the basic living care and closely related medical care of the chronically disabled by raising funds through mutual assistance". Its connotation can be divided into three aspects: (1) "long-term" refers to a longer period of nursing. (2) "Care" mainly includes basic living care and medical care. (3) "Insurance" mainly refers to social insurance, but does not exclude commercial insurance.

\section{RESEARCH ON THE DEVELOPMENT MODEL OF LONG-TERM CARE INSURANCE IN CHINA}

Domestic scholars' early research on long-term care insurance mainly focused on the choice of development model. Based on the analysis and comparison of long-term care insurance practices in various countries, they deeply discussed whether China should adopt the commercial insurance model or the social insurance model.

By comparing the development models of the United States, Japan and Germany, Jiang Hong points out that, based on the current economic development situation in China, we can only adopt a model with commercial insurance as the main one and social insurance as the supplementary one, and implement different models according to regions and industries. ${ }^{[1]}$ Dai Weidong and Dong Congwen, on the basis of drawing lessons from foreign experience, put forward the " $3+1$ " model: socialized nursing insurance (basic), community nursing assistance system, family function, plus commercial nursing insurance. ${ }^{[2]}$ By comparing the long-term care insurance systems of the United States and Japan, Jing Tao proposes a "three-step" model: commercial insurance -- social insurance as the main, commercial insurance as the auxiliary -- mandatory long-term care insurance for the whole people. ${ }^{[3]}$ 
To sum up, in the early studies, domestic scholars mainly preferred to adopt social long-term care insurance, but did not exclude commercial insurance, and emphasized the role of family and community.

\section{RESEARCH ON THE INFLUENCING FACTORS OF THE DEMAND FOR LONG-TERM CARE INSURANCE IN CHINA}

While demonstrating the development model, some scholars began to analyze the demand influencing factors of the domestic long-term care insurance system. The analysis of demand influencing factors mainly adopts quantitative research and can be divided into macro and micro levels.

\subsection{Macro Level}

By establishing a logarithmic linear model, Jing Tao et al. conclude that social security expenditure is in direct proportion to the demand for long-term care insurance, while national per capita income, interest rate and inflation have no significant influence on the demand. ${ }^{[4]}$ Xie Xiaolu uses the panel data of 21 provincial-level administrative regions in China from 2008 to 2010 to conclude that factors such as population aging, family structure and education level have no significant economic impact on the demand for long-term care insurance in China due to the traditional concept. ${ }^{[5]}$ Using a multi-layer linear model, Peng Rong concludes that regional differences, economic ability, willingness of service providers, and health status of the elderly have a significant impact on the long-term care insurance demand of the elderly in China, while gender, age, education level, marital status and other factors have no significant impact. ${ }^{[6]}$

\subsection{Micro Level}

Dai Weidong and Tao Xiubin use multiple Logit regression model to analyze the young people in Jiangsu and Anhui provinces, and conclude that regional differences have no significant impact on demand, while education level, fear of no one to take care of the elderly, fear of poor economy in the future, and lack of understanding of the system have significant impact on demand. ${ }^{[7]}$ Using Logit/Probit model, Chen Dongmei and Yuan $\mathrm{Yi}$ Haodiao conclude that individual willingness factors, medical demand factors and price factors have significant influences on demand, while savings, income, marriage and family factors are not. ${ }^{[8]}$ Using logistic regression model, Cao Xinbang and Chen Qiang conclude that individual characteristics (living area, age, health status, occupational nature), economic factors (family annual income), and awareness (service quality of pension service institutions, risk awareness, and cognition of long-term care insurance) have significant influences on insurance participation intention, while the influence of family size, number of children, living style and family chronic diseases are not significant. ${ }^{[9]}$

In summary, the macro-level research mainly uses linear model to analyze the provincial panel data, while the micro-level research mainly uses the logistic model to analyze the sample data obtained from the questionnaire. There are differences in the results obtained by different scholars in both macro and micro researches.

\section{STUDY ON THE NECESSITY AND FEASIBILITY OF LONG-TERM CARE INSURANCE}

Based on the analysis of the factors influencing the demand for long-term care insurance in China, some scholars focused on the necessity and feasibility of implementing long-term care insurance in China. Domestic academic circles have reached a consensus on the necessity of implementing long-term care insurance. Under the circumstances of aging population, weakened family function, rising long-term care cost and imperfect social security system, China needs to construct long-term care insurance to solve the problem of long-term care. In terms of feasibility, China has a certain foundation of elderly care institutions, and a lot of international experience for reference. But there are also some obstacles: (1) the public nursing insurance awareness is weak, (2) the relevant legislation is not sound, (3) the lack of professional nursing staff, and (4) adverse selection and moral hazard. In the long run, China's regional development is extremely unbalanced. It is difficult to build a unified long-term care social insurance at the present stage. The central government should first issue a general policy document, and then each region ought to carry out pilot work according to the actual situation, and gradually realize the unification of policies. ${ }^{[10]}$

\section{STUDY ON THE PILOT OF LONG-TERM CARE INSURANCE IN CHINA}

In June 2016, the Ministry of Human Resources and Social Security issued "the Guiding Opinions on the Pilot Implementation of the Long Term Care Insurance System”. Fifteen cities, including Shanghai and Qingdao, were selected as pilot cities, and domestic scholars also started to study the pilot.

\subsection{Study on Pilot Effectiveness}

Domestic scholars evaluates the effectiveness of long-term care insurance pilots in different cities. Although the policies of each pilot are different, on the 
whole: (1) The basic framework of long-term care insurance system has been established. (2) The "institutionalization" of long-term care insurance has been realized, and the financial burden on individuals and families has been reduced. (3) The "socialization" of long-term nursing services has been promoted, and the rapid development of home care services has been promoted. (4) The "specialization" and "diversification" of the main body of service supply have been promoted, and the optimal utilization of medical resources has been accelerated.

\subsection{Study on System Omission}

The pilot process also exposes some system omissions. Scholars generally believe that there are problems in the following aspects: (1) The coverage is too narrow, mainly for medical insurance participants of urban employees. (2) The financing channels are excessively dependent on the medical insurance fund, and the financing standards vary greatly between regions. (3) Funds are difficult to achieve the balance of income and expenditure. (4) The service content is too single, and the service supply and demand do not match. (5) Disability assessment standards are not uniform and lack of specific provisions. ${ }^{[1]}$

\subsection{Research on Reform Path}

For the future development direction of China's long-term care insurance, domestic scholars have put forward different reform paths based on the analysis of the pilot situation and the reference of foreign experience, which mainly include the following aspects: (1) Expand the coverage of insured people, and build long-term care services for the whole people. (2) Establish a diversified financing mechanism and gradually realize the independence of the long-term care insurance system. (3) Construct scientific disability assessment criteria and assessment procedures. (4) Introduce market competition mechanism to develop commercial nursing insurance. (5) Increase the training of professional nursing staff to improve the quality of nursing services. (6) Give full play to the role of the community and the family. (7) Enhance the concept of nursing prevention for the elderly. ${ }^{[12]}$

\section{CONCLUSION}

Domestic scholars' research on long-term care insurance has experienced a process from the shallow to the deep, among which, different scholars have different views on the influencing factors of long-term care insurance demand, which still needs to be further explored. At present, the pilot process of long-term care insurance in China has been continuously promoted. While bringing a series of results, some system omissions have also been exposed. It is necessary to design and improve the system based on more mature operation experience of long-term care insurance.

\section{REFERENCES}

[1] Jiang Hong. The Choice of the Development Model of China's Long-term Care Insurance. Southwest Finance, 2007, 0(1): 61-62. DOI: 10.3969/j.issn.1009-4350.2007.01.025

[2] Dai Weidong, Dong Congwen. Analysis of the Prospects of Commercial Nursing Insurance in China-Also on the Future Model of Life Nursing System for the Elderly in China. Academic Exchange, (2007): 120-125. DOI: CNKI: SUN: XSJL.0.2007-04-031

[3] Jing Tao. Establishing a Long-term Care Insurance System Model Suitable for China's National Conditions. Insurance Research, (2010): 78-84. DOI: CNKI: SUN: BXYJ.0.2010-04-011

[4] Jing Tao, Wang Jingtao, Li Sha. An Empirical Analysis of the Impact on the Demand for Long-term Care Insurance in China. Journal of Beijing Technology and Business University (Social Science Edition), 2011, 226(6): 90-96. DOI: $10.3969 /$ j.issn.1009-6116.2011.06.015

[5] Xie Xiaolu. Analysis of the Influencing Factors of the Demand for Long-term Care Insurance in China. Finance and Economy, 2012, 0(11): 75-78. DOI: 10.3969/j.issn.1006-169X.2012.11.020

[6] Peng Rong. Satisfaction of the Long-term Care Needs of the Elderly in Our Country and its influencing factors. Chinese Journal of Gerontology, 2012, 32(14): 3005-3008. DOI: 10.3969/j.issn.1005-9202.2012.14.044.

[7] Dai Weidong, Tao Xiubin. Young People's Willingness to Long-term Care Insurance Demand and its Influencing Factors -- a Comparative Study Based on the Survey of Jiangsu and Anhui Provinces. Chinese Health Service Management, (2012): 39-41. DOI: CNKI: SUN: ZWSG.0.2012-05-013

[8] Chen Dongmei, Yuan Yihao. Analysis of Our Country's Long-term Care Insurance Needs Under the Background of Population Aging: Taking Shanghai as an Example. Journal of Shanghai University (Social Science Edition), (2015): 19-28. DOI: CNKI: SUN: SHDS.0.2015-06-003

[9] Cao Xinbang, Chen Qiang. Analysis of Influencing Factors of China's Long-term Care Insurance Demand. China Population Science, (2014): 104-111+130. DOI: CNKI: SUN: ZKRK.0.2014-04-011 
[10] Li Bing. Discussion on the Feasibility and Necessity of Establishing a Long-term Care Insurance System in China. Reform and Strategy, (2015): 69-72. DOI: CNKI: SUN: GGZY.0.2015-03-016

[11] Zhong Junchi, Zhang Duoling, Zhang Ying. Problems and Considerations in the Construction of the Long-term Care Insurance System for the Elderly in China. Medicine and Philosophy(A), 2017, 38(5A): 43-45. DOI: 10.12014/j.issn.1002-0772.2017.05a.13.

[12] Lu Ting. The Development Status and Thinking of China's Long-term Care Insurance-Based on the Practice of 15 Cities across the Country[J].Chinese Health Service Management, (2019): 33-38. DOI: CNKI: SUN:ZWSG.0.2019-01-011 